\title{
Cost minimization of a ring-stiffened conical shell loaded by external pressure
}

\author{
J. Farkas ${ }^{1}$, K. Jármai ${ }^{2}$, F. Orbán ${ }^{3}$ \\ ${ }^{1}$ Professor emeritus, University of Miskolc, ${ }^{2}$ Professor, University of Miskolc, ${ }^{3}$ Professor, Mihály Pollack \\ Engineering College, University of Pécs, Hungary
}

\begin{abstract}
A ring-stiffened slightly conical shell is optimized for external pressure according to the design rules of Det Norske Veritas. The whole length and the different two end radii of the shell are given. The shell is divided to $n$ equidistant segments with one stiffener in each segment. Each segment has different shell thickness determined using a buckling constraint and each ring-stiffener of welded square box section is designed by means of the required moment of inertia. The optimal number of shell segments $\left(n_{\text {opt }}\right)$ is determined by means of costs calculated for a series of $n$. The cost function includes the material, fabrication and painting costs. The shell membrane stresses are determined also by finite element method.
\end{abstract}

Key words: conical shell, shell buckling, fabrication cost, minimum cost design, economy of welded structures.

\section{Introduction}

Conical shells are applied in numerous structures e.g. in submarine and offshore structures, aircraft, tubular structures, towers, tanks, etc. Their structural characteristics are as follows.

- Material: steels, Al-alloys, fibre-reinforced plastics,

- Geometry: slightly conical (transition parts between two circular shells), strongly conical (storage tank roofs), truncated,

- Stiffening: ring-stiffeners, stringers, combined, equidistant, non-equidistant,

- Stiffener profile: flat, box, T-, L-,Z-shape,

- Loads: external pressure, axial compression, bending, torsion, combined,

- Fabrication technology: welding, riveting, bolting, gluing. 
Klöppel and Motzel [1] have carried out buckling experiments with truncated unstiffened and ring-stiffened steel conical shell specimens and proposed simple formulae for critical buckling stress.

Rao and Reddy [2] have worked out an optimization procedure for minimum weight of axially loaded, simply supported, stiffened truncated conical shells. Rectangular ringstiffeners and stringers are used and constraints on shell buckling as well as on natural frequency are considered.

In the book written by Ellinas et al. [3] experimental results and design of stiffened conical shells are treated considering several load cases.

Spagnoli has written a $\mathrm{PhD}$ thesis on buckling behaviour and design of stiffened conical shells under axial compression [4]. Rectangular stringers are considered. Later Spagnoli also with co-authors $[5,6,7]$ has published other articles in this field.

Chryssanthopoulos et al. [8] have used finite element method for buckling analysis of stringer-stiffened conical shells in compression.

Singer et al. [9] have given a detailed description of experiments carried out with stiffened conical shell models.

Minimum cost design has been worked out for ring-stiffened circular cylindrical shell, subject to external pressure in our study $[10,11]$.

In the present study we select the following structural characteristics: steel, slightly conical shell, ring-stiffeners of welded square box section to avoid tripping, equidistant stiffening, external pressure, welding. Design rules of Det Norske Veritas [12,13] are applied for shell and stiffener buckling constraints.

The variables to be optimized are as follows: number of shell segments $(n)$ (Fig.1), shell thicknesses $\left(t_{i}\right)$, dimensions of ring-stiffeners $\left(h_{i}, t_{r i}\right)$. The number of stiffeners is $n+1$, since stiffeners should be used at the ends of the shell, thus, two stiffeners are used in the first shell segment. The ring stiffeners are placed in a small distance from the circumferential welds connecting two segments to allow the inspection of welds, this is marked in Figure 1 by dotted lines. The cost function includes the cost of material, assembly, welding and painting and is formulated according to the fabrication sequence.

The optimization process has the following parts:

(a) design of thicknesses for each shell segment given by two radii $\left(R_{i}\right.$ and $\left.R_{i+1}\right)$ using the shell buckling constraint,

(b) design of ring-stiffeners for each shell segment using the stiffener buckling constraint,

(c) cost calculation for each shell segment and for the whole shell structure. 
These design steps should be carried out for a series of segment-numbers. On the basis of calculated costs the optimum solution corresponding to the minimum cost can be determined.

\section{Design of shell thicknesses}

According to DNV rules [13], for shell segments between two ring-stiffeners of radii $R_{i}$ and $R_{i+1}$ the buckling constraint valid for circular cylindrical shells with equivalent radius

$$
\begin{aligned}
& R_{e i}=\frac{R_{i+1}+R_{i}}{2 \cos \alpha}, \cos \alpha=\frac{1}{\sqrt{\tan ^{2} \alpha+1}} \\
& \tan \alpha=\frac{R_{n+1}-R_{1}}{L_{0}}, R_{i+1}=L_{i} \tan \alpha+R_{i}, L_{i}=\frac{L_{0}}{n}
\end{aligned}
$$

and equivalent thickness

$$
t_{e i}=t_{i} \cos \alpha
$$

The normal stress due to external pressure in a shell segment should be smaller than the critical buckling stress

$$
\begin{aligned}
& \sigma_{i}=\frac{\gamma_{b} p R_{i}}{t_{e i}} \leq \sigma_{c r i}=\frac{f_{y 1}}{\sqrt{1+\lambda_{i}^{4}}}, \quad \lambda_{i}=\sqrt{\frac{f_{y 1}}{\sigma_{E i}}} \\
& \sigma_{E i}=\frac{C_{i} \pi^{2} E}{12\left(1-v^{2}\right)}\left(\frac{t_{e i}}{L_{e i}}\right)^{2}, L_{e i}=\frac{L_{i}}{\cos \alpha}
\end{aligned}
$$

where

$$
C_{i}=4 \sqrt{1+\left(\frac{0.6 \xi_{i}}{4}\right)^{2}}, \xi_{i}=1.04 \sqrt{Z_{i}}, Z_{i}=\frac{L_{e i}^{2}}{R_{e i} t_{e i}} \sqrt{1-v^{2}}
$$

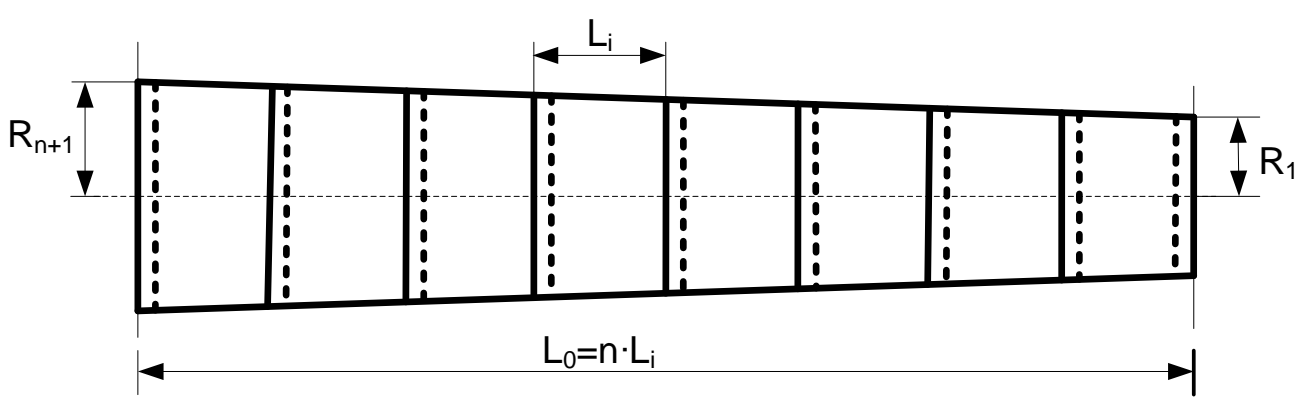



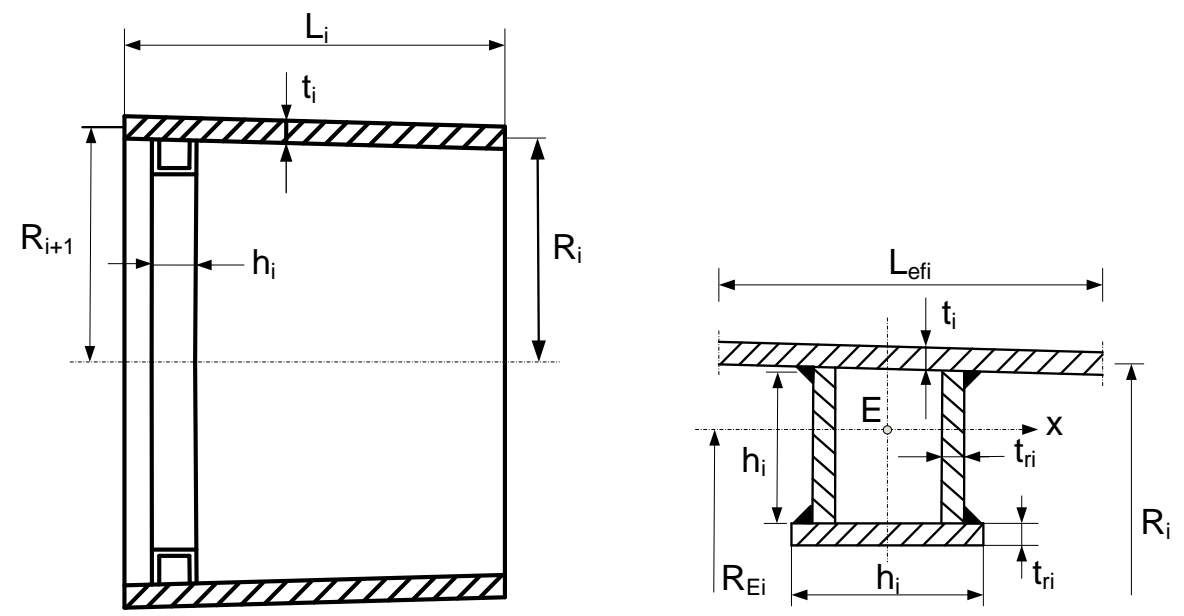

Figure 1. The main dimensions of the conical shell - a shell segment with the ring-stiffener of welded square box section

Using Eqs (5), Eq (6) can be written in the form of

$$
C_{i}=4 \sqrt{1+0.023214 \frac{L_{e i}^{2}}{R_{e i} t_{e i}}}
$$

From the shell buckling constraint Eq (4) the unknown $t_{i}$ can be calculated using a Mathcad algorithm.

\section{Design of a ring-stiffener for each shell segment}

For ring-stiffeners a square box section welded from 3 parts is selected to avoid tripping, which is dangerous failure mode for open-section stiffeners (Fig.1).

The constraint on local buckling of the compressed stiffener flange according to Eurocode $3[14]$ is expressed by

$$
t_{r i} \geq \delta h_{i}, 1 / \delta=42 \varepsilon, \varepsilon=\sqrt{235 / f_{y}}
$$

for $f_{y}=355 \mathrm{MPa} 1 / \delta=34$.

Calculating with Eq (8) as equality, the only unknown for a square ring-stiffener is the height $h_{i}$. This dimension can be determined from the stiffener buckling constraint relating to the required moment of inertia of a stiffener section about the axis $x$ of the point $\mathrm{E}$, which is the gravity center of the cross-section including the 3 stiffener parts and the effective part of the shell (Fig.1) 


$$
I_{x i} \geq I_{r e q i}=\frac{\gamma_{b} p R_{i} R_{E i}^{2} L_{e f i}}{3 E}\left[2+\frac{3 E y_{E i} 0.005 R_{i}}{R_{E i}^{2}\left(f_{y 1} / 2-\sigma_{i}\right)}\right]
$$

where

$$
\begin{aligned}
I_{x i} & =\frac{\delta h_{i}^{4}}{6}+3 \delta h_{i}^{2} h_{i}^{2} \frac{L_{e f i} t_{i}}{3 \delta h_{i}^{2}+L_{e f i} t_{i}}+\frac{L_{e f i} t_{i}^{3}}{12}, \\
y_{E i} & =\frac{L_{e f i} t_{i}\left(h_{i}+t_{i} / 2\right)+\delta h_{i}^{3}}{3 \delta h_{i}^{2}+L_{e f i} t_{i}} \\
L_{e f i} & =\min \left(L_{i}, L_{e f 0 i}\right), L_{e f 0 i}=1.56 \sqrt{R_{i} t_{i}} \\
R_{E i} & =R_{i}-\left(h_{i}+\frac{t_{i}}{2}+\frac{\delta h_{i}}{2}-y_{E i}\right)
\end{aligned}
$$

The required $h_{i}$ can be calculated from Eq (9).

We do not considered a significant difference in end restraints for the two end segments.

\section{The cost function}

The cost function is formulated according to the fabrication sequence as follows [11].

(1) Forming of 3 plate elements for shell segments into slightly conical shape $\left(K_{F 0}\right)$.

(2) Welding 3 curved shell elements into a shell segment with GMAW-C (gas metal arc welding with $\left.\mathrm{CO}_{2}\right)$ butt welds $\left(K_{F 1}\right)$.

(3) Welding of $n+1$ ring-stiffeners each from 3 elements with 2 GMAW-C fillet welds $\left(K_{F 2}\right)$.

(4) Welding of a ring-stiffener into each shell segment with 2 GMAW-C fillet welds $\left(K_{F 3}\right)$.

(5) Assembly of the whole stiffened shell structure from $n$ shell segments $\left(K_{F 4 A}\right)$.

(6) Welding of $n$ shell segments to form the whole shell structure with $n$ - 1 circumferential GMAW-C butt welds $\left(K_{F 4 W}\right)$.

(7) Painting of the whole shell structure from inside and outside $\left(K_{P}\right)$.

The total cost includes the cost of material, assembly, welding and painting

$$
\begin{aligned}
& K=K_{M}+K_{F 0}+K_{F 1}+K_{F 2}+K_{F 3}+K_{F 4}+K_{P} \\
& K_{M}=k_{M} \rho V, k_{M}=1.0 \$ / \mathrm{kg}
\end{aligned}
$$

The volume of the whole structure includes the volume of shell segments $\left(V_{l i}\right)$ and ringstiffeners $\left(V_{r i}\right)$

$$
\begin{aligned}
& V=\sum_{i=1}^{n} V_{1 i}+\sum_{i=1}^{n+1} V_{r i} \\
& K_{F 0 i}=k_{F} \Theta_{f} e^{\mu}, \mu=6.8582513-4.527217 t_{i}^{-0.5}+0.009541996\left(2 R_{e i}\right)^{0.5},
\end{aligned}
$$




$$
K_{F 0}=\sum_{i=1}^{n} K_{F 0 i}
$$

where the factor of fabrication difficulty is taken as $\Theta_{\mathrm{f}}=3$ and the steel density is $\rho=7.85 \times 10^{-6} \mathrm{~kg} / \mathrm{mm}^{3}, k_{F}=1.0 \$ / \mathrm{min}$.

$$
\begin{aligned}
& K_{F 1 i}=k_{F}\left[\Theta \sqrt{3 \rho V_{1 i}}+1.3 \times 0.152 \times 10^{-3} t_{i}^{1.9358} \times 3 L_{e i}\right], K_{F 1}=\sum_{i=1}^{n} K_{F 1 i} \\
& V_{1 i}=2 \pi R_{e i} L_{e i} t_{i} \\
& K_{F 2 i}=k_{F}\left[\Theta \sqrt{3 \rho V_{r i}}+1.3 \times 0.3394 \times 10^{-3} a_{w i}^{2} x 4 \pi\left(R_{i}-h_{i}\right)\right]
\end{aligned}
$$

where

$$
V_{r i}=4 \pi t_{r i} h_{i}\left(R_{i}-h_{i} / 2\right)+2 \pi t_{r i} h_{i}\left(R_{i}-h_{i}\right)
$$

the difficulty parameter is $\Theta=3$. At different parts this parameter can be also different, for simple planar structures is can be $\Theta=2$, for more complicated spatial structures it can be $\Theta=4$.

the fillet weld size $a_{w i}=0.7 \delta h_{i}$.

$$
\begin{aligned}
& K_{F 2}=\sum_{i=1}^{n+1} K_{F 2 i} \\
& \left.K_{F 3 i}=k_{F} \mid \Theta \sqrt{2 \rho V_{3 i}}+1.3 x 0.3394 \times 10^{-3} a_{w i}^{2} x 4 \pi R_{i}\right], V_{3 i}=V_{1 i}+V_{r i} \\
& K_{F 3}=\sum_{i=1}^{n+1} K_{F 3 i} \\
& K_{F 4}=K_{F 4 A}+K_{F 4 W}, K_{F 4 A}=k_{F} \Theta \sqrt{n \rho V}, K_{F 4 W}=\sum_{i=2}^{n} K_{F 4 W i} \\
& K_{F 4 W i}=1.3 k_{F} x 0.152 \times 10^{-3} t_{i}^{1.9358} x 2 \pi R_{i} \\
& K_{P}=K_{P 1}+\sum_{i=1}^{n+1} K_{P i}, K_{P 1}=k_{P} 4 \pi \frac{R_{\max }+R_{1}}{2} L_{0} \\
& K_{P i}=k_{P} 4 \pi h_{i}\left(R_{i}-h_{i} / 2\right) \\
& k_{P}=2 \times 14.4 \times 10^{-6} \$ / \mathrm{mm}^{2} .
\end{aligned}
$$

We could consider also the minimum waste of plate in cutting process, but in this case we considered only the minimum cost of the structure. Minimum waste can be considered, when more different structures are made simultaneously.

\section{Numerical data (Figure 1)}

Total shell length $L=15000$, side radii $R_{\min }=R_{l}=1850$ and $R_{\max }=R_{n+l}=2850 \mathrm{~mm}$, yield stress of steel $f_{y}=355 \mathrm{MPa}$, with a safety factor for yield stress $f_{y l}=f_{y} / 1.1$, external pressure intensity $p=0.5 \mathrm{MPa}$, safety factor for loading $\gamma_{\mathrm{b}}=1.5$, Poisson ratio $v=0.3$, elastic modulus $E=2.1 \times 10^{5} \mathrm{MPa}$. 


\section{Results of the optimization}

The detailed calculations are carried out for numbers of shell segments $n=3-15$. The corresponding material and total costs are summarized in Table 1.

Table 1. The material and total costs in $\$$ for investigated numbers of shell segments. The optima are marked by bold letters

\begin{tabular}{ccccccccc}
\hline$n$ & 3 & 4 & 5 & 6 & 8 & 10 & 12 & 15 \\
\hline$K_{M}$ & 48540 & 43540 & 40350 & 36830 & 33390 & 31390 & $\mathbf{2 9 8 4 0}$ & 31192 \\
$K$ & 85390 & 82360 & 81430 & $\mathbf{7 9 2 1 0}$ & 80260 & 82120 & 84811 & 95818 \\
\hline
\end{tabular}

It can be seen that the optimum number of shell segments for material cost is $n_{\text {Mopt }}=12$ and for total cost $n_{\text {opt }}=6$. This difference is caused by the fact that the fabrication (assembly, welding and painting) cost represents a large amount of total cost. The cost data show that, in the fabrication cost, the forming of plate elements into shell shape, welding and painting have a significant part.

In order to characterize the dimensions of the optimum structure, the main data are given in Table 2.

Table 2. Main dimensions (in $\mathrm{mm}$ ) of the optimum shell structure $(n=6)$

\begin{tabular}{ccccc}
\hline$i$ & $R_{i}$ & $t_{i}$ & $h_{i}$ & $t_{r i}$ \\
\hline 1 & 1850 & 18 & 121 & 4 \\
2 & 2017 & 19 & 132 & 4 \\
3 & 2184 & 20 & 143 & 5 \\
4 & 2351 & 20 & 156 & 5 \\
5 & 2518 & 21 & 155 & 5 \\
6 & 2685 & 22 & 153 & 5 \\
7 & 2852 & 23 & 152 & 6 \\
\hline
\end{tabular}

The fabrication and painting cost components for the optimum structure are given in Table 3 .

Table 3. Fabrication and painting cost components in $\$$ for the optimum structure of $n=6$

\begin{tabular}{cccccccc}
\hline$K_{F 0}$ & $K_{F 1}$ & $K_{F 2}$ & $K_{F 3}$ & $K_{F 4 A}$ & $K_{F 4 W}$ & $K_{P 1}$ & $\Sigma K_{P i}$ \\
\hline 11981 & 5330 & 1329 & 3202 & 1410 & 5681 & 12760 & 689 \\
\hline
\end{tabular}




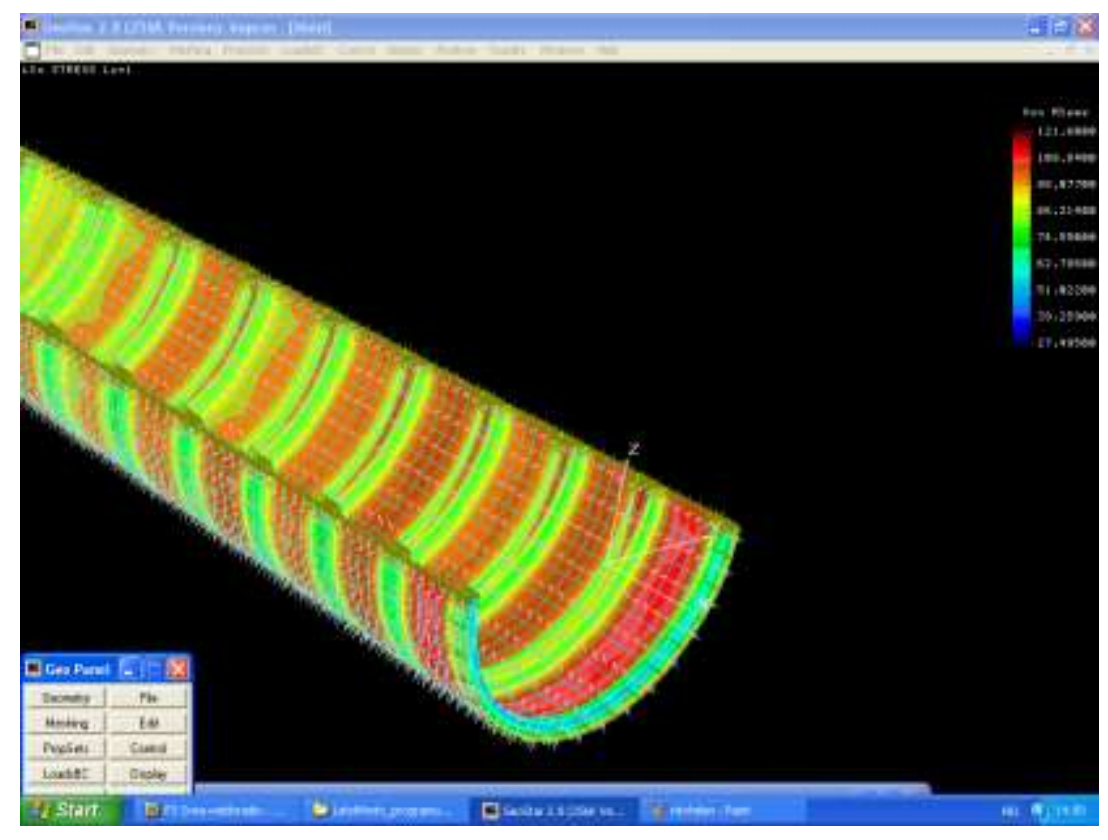

Figure 2. Finite element results of the conical shell stresses

The membrane stresses in shell segments have been calculated also by finite element method (FEM). The COSMOSM 2.8 (version $256 \mathrm{~K}$ ) program with finite elements SHELL4 has been used. Number of elements was 2466, and number of nodes was 2413 . The material was linear elastic and the Gauss integral has been used.

For $n=10$ the stresses are 99-109 MPa, while those in optimization process are 102-124 MPa, thus, a good agreement is among these values. Figure 2 shows the membrane stress values obtained by FEM. According to the FEM linear buckling analysis, which does not consider the effect of initial imperfections and residual welding stresses, the critical external pressure is 1.85 $\mathrm{MPa}$, so the optimized structure is safe enough against buckling.

\section{Conclusions}

The optimum design problem is solved for a slightly conical shell loaded in external pressure with equidistant ring-stiffeners of welded square box section. The optimum number of shell segments is found, which minimizes the cost function and fulfils the design constraints.

The thickness of each shell segment is calculated from the shell buckling constraint. This constraint is similar to that for circular cylindrical shells, but equivalent thickness and segment length is used according to the DNV design rules [13].

The dimensions of ring-stiffeners for each shell segment are determined on the basis of the ring buckling constraint. This constraint is expressed by the required moment of inertia of the ring-stiffener cross-section.

The cost function includes the cost of material, forming of plate elements into shell shape, assembly, welding and painting. The fabrication cost function is formulated according to the fabrication sequence. The forming, welding and painting costs play an important role in the total cost. 
The cost difference between the maximum and minimum cost in the investigated range of shell segment number $(n=3-15)$ is $(95818-79210) / 95818 \times 100=17 \%$, thus, a significant cost savings can be achieved by optimization.

The ring-stiffening is very effective, since the unstiffened shell needs a thickness of 42 $\mathrm{mm}$, which is unrealistic for fabrication.

\section{Acknowledgement}

The research work was supported by the József Öveges scholarship OMFB 01385/2006, given by the National Office of Research and Technology (NKTH) and the Agency for Research Fund Management and Research Exploitation (KPI).

\section{References}

1. Klöppel,K. \& Motzel,E. (1976) Traglastversuche an stählernen, unversteiften und ringversteiften Kegelstumpfschalen. Teil 1. Versuchsbericht. Stahlbau 45, No.10. 289301.

2. Rao,S.S. \& Reddy,E.S. (1981) Optimum design of stiffened conical shells with natural frequency constraints. Computers \& Structures 14, No.1-2, 103-110.

3. Ellinas,C.P., Supple,W.J. \& Walker,A.C. (1984) Buckling of offshore structures. London, etc. Granada Publ.

4. Spagnoli,A. (1997) Buckling behaviour and design of stiffened conical shells under axial compression. PhD thesis, University of London, London.

5. Spagnoli,A. \& Chryssanthopoulos,M.K. (1999a) Buckling design of stringer-stiffened conical shells in compression. J. Struct. Eng. ASCE 125, No.1. 40-48.

6. Spagnoli,A. \& Chryssanthopoulos,M.K. (1999b) Elastic buckling and postbuckling behaviour of widely-stiffened conical shells under axial compression. Eng. Struct. 21, No.9. 845-855.

7. Spagnoli,A. (2001) Different buckling modes in axially stiffened conical shells. Eng. Struct. 23, No.8. 957-965.

8. Chryssanthopoulos,M.K., Poggi,C. \& Spagnoli,A. (1998) Buckling design of conical shells based on validated numerical models. Thin-walled Struct. 31, No.1-3, 257-270.

9. Singer,J., Arbocz,J. \& Weller,T. (2002) Buckling experiments: experimental methods in buckling of thin-walled structures. Vol.2. Shells, built-up structures, composites and additional topics. New York, Wiley \& Sons.

10. Farkas,J., Jármai,K., Snyman,J.A. \& Gondos,Gy. (2002) Minimum cost design of ringstiffened welded steel cylindrical shells subject to external pressure. Proc. 3rd European Conf. Steel Structures, Coimbra, 2002, eds. Lamas,A. and Simoes da Silva, L. Universidade de Coimbra, 513-522.

11. Farkas,J. \& Jármai,K. (2003) Economic design of metal structures. Rotterdam, Millpress.

12. Det Norske Veritas (DNV) (1995) Buckling strength analysis. Classification Notes No.30.1. Høvik, Norway.

13. Det Norske Veritas (2002) Buckling strength of shells. Recommended Practice DNV-RPC202. Høvik, Norway.

14. Eurocode 3 (2002) Design of steel structures. Part 1-1: General structural rules. Brussels, CEN. 